\title{
Peak flow variation in childhood asthma: relationship to symptoms, atopy, airways obstruction and hyperresponsiveness
}

\author{
P.L.P. Brand*, E.J. Duiverman**, D.S. Postma+, H.J. Waalkens*, K.F. Kerrebijn++, \\ E.E.M. van Essen-Zandvliet ${ }^{++}$, and the Dutch CNSLD Study Group
}

\begin{abstract}
Peak flow variation in childhood asthma: relationship to symptoms, atopy, airways obstruction and hyperresponsiveness. P.L.P. Brand, E.J. Duiverman, D.S. Postma, H.J. Waalkens, K.F. Kerrebijn, E.E.M. van Essen-Zandvliet, and the Dutch CNSLD Study Group. CERS Journals Ltd 1997.

ABSTRACT: Although home recording of peak expiratory flow (PEF) is considered useful in managing asthma, little is known about the relationship of PEF variation to other indicators of disease activity. We examined the relationship of PEF variation, expressed in various ways, to symptoms, atopy, level of lung function, and airways hyperresponsiveness in schoolchildren with asthma.

One hundred and two asthmatic children (aged 7-14 yrs) recorded symptoms and PEF (twice daily) in a diary for 2 weeks after withdrawal of all anti-inflammatory maintenance medication. PEF variation was expressed as amplitude \% mean, as standard deviation and coefficient of variation of all recordings, and as low \% best (lowest PEF as percentage of the highest of all values).

Atopy and level of forced expiratory volume in one second (FEV1) \% predicted were not significantly related to $P E F$ variation. The provocative dose of histamine causing a $20 \%$ fall in FEV1 (PD20) and symptom scores were significantly, but weakly, related to PEF variation. The index, low \% best, proved easy to calculate and effective in identifying a short-term episode of reduced PEF.

We conclude that peak expiratory flow variation in children with stable, moderately severe asthma is significantly, but weakly, related to symptoms and airways hyperresponsiveness. These three phenomena, therefore, all provide different information on the actual disease state. Expressing peak expiratory flow variation as low \% best is easy to perform and appears to be clinically relevant.

Eur Respir J 1997; 10: 1242-1247.
\end{abstract}

*Dept of Paediatric Pulmonology, Beatrix Children's Hospital, Groningen, The Netherlands. **Dept of Paediatric Pulmonology, Juliana Children's Hospital, the Hague, The Netherlands. +Dept of Pulmonology, University Hospital, Groningen, The Netherlands. ${ }^{++}$Dept of Paediatric Respiratory Medicine, Sophia Children's Hospital, Rotterdam, The Netherlands.

Correspondence: P.L.P. Brand

Dept of Paediatric Pulmonology

Beatrix Children's Hospital

P.O. Box 30.001

9700 RB Groningen

The Netherlands

\section{Keywords: Asthma}

child

peak expiratory flow

peak flow variation

Received: November 111996

Accepted after revision February 161997
Home recording of peak expiratory flow (PEF) is considered to be useful in managing childhood asthma. Recent consensus reports from the USA [1] and the UK $[2,3]$ propose the use of PEF recordings as a basis for modifying anti-inflammatory treatment or seeking medical help. The underlying assumption for this practice is that changes in PEF are a reflection of airways hyperresponsiveness and asthma severity [4]. Unfortunately, very few data are available on the relationship of PEF variation to other indices of disease activity in childhood asthma. In a population-based study of children with mild asthmatic symptoms, PEF variation was weakly associated with the degree of methacholine responsiveness, with symptom scores, and with the presence of atopy [5]. Similar results were found in a study of children with moderately severe asthma undergoing immunotherapy [6]. Treatment was not standardized in either of these studies. This might be important, as it has been shown that maintenance therapy with inhaled steroids considerably reduces PEF variation [7, 8].

There is no agreement on the best way of analysing and expressing PEF values as recorded in a diary. A commonly used method to express diurnal changes is to divide the difference between morning and evening values by their mean, averaged over a period of time (amplitude \% mean). Although this index has been used in population studies [9] and clinical trials [6], its use has been criticized because isolated important drops in PEF are "averaged out" and may be lost in analysis [10]. In order to increase the appreciation of such isolated or short-term reductions of PEF, variation can be expressed as a standard deviation (SD) or coefficient of variation $(\mathrm{CV})$ of all results obtained over a period of time $[5,10]$. Another approach is to compute the patient's lowest PEF as a percentage of his/her highest value, as is currently applied in self-management plans [1-3, 11]. Next to diurnal changes in PEF, day-to-day variation can be calculated. The relative merits of these different ways of expressing PEF variation have not yet been studied in children with asthma.

In this report, we examine the cross-sectional relationship of PEF variation, expressed in 5 different ways, to asthma symptom severity, to degree of airways obstruction and hyperresponsiveness, and to markers of atopy. 
The study sample comprised schoolchildren with clinically stable asthma, who were on standardized therapy (inhaled bronchodilators only, all anti-inflammatory therapy withdrawn) [7].

\section{Methods}

For this report, baseline data of a long-term study on inhaled steroids in childhood asthma were used [7]. Patients were recruited for this study between 1987 and 1989, when anti-inflammatory treatment was commonly, but not universally, prescribed to children with chronic asthma in the Netherlands. Details of patient recruitment and study methods have been published previously [7]. The main inclusion criteria were: a clinical diagnosis of asthma; demonstrable airways obstruction (defined as a forced expiratory volume in one second (FEV1) 55$90 \%$ of predicted; and/or a FEV1/forced vital capacity (FVC) ratio of 0.5-0.75); and airways hyperresponsiveness (defined as a provocative dose of histamine causing a $20 \%$ fall in FEV1 $($ PD20) $\leq 150 \mu \mathrm{g}$; see method below) after withdrawal of anti-inflammatory therapy; and willingness to participate in a 2 year clinical trial.

Children with asthma, aged 7-14 yrs, entered the baseline period of the study after tapering-off and withdrawing all pulmonary maintenance medication. For a period of 4 weeks, they used only inhaled $\beta_{2}$-agonists on demand. During the last 2 weeks of this baseline period, they kept a diary of symptoms (on a 12-point scale), $\beta_{2}$-agonist use and PEF. During the entire two year trial, patients were asked to fill out such two week diaries before each two monthly out-patient clinic visit. These two week periods were chosen as a compromise between no diary data at all (which was undesirable) and a daily diary kept for two full years (which was regarded as asking too much of the patients) [12]. In this paper, only the baseline diary data on symptoms and PEF will be reported.

All patients received a new mini-Wright PEF meter and standardized instructions on how to use it. PEF was recorded between 07.00 and $09.00 \mathrm{~h}$ and between 17.00 and $19.00 \mathrm{~h}$, before inhaling $\beta_{2}$-agonist. On each occasion, the best of three blows was recorded in the diary. At the end of the 2 week period, all patients demonstrated a PEF manoeuvre to ensure that a reliable technique had been used.

At the beginning and the end of the baseline period, patients visited the out-patient clinic for further characterization, including a standardized respiratory questionnaire, physical examination, spirometry, histamine challenge, blood eosinophil counts and determination of total serum immunoglobulin E (IgE) levels and radioallergosorbent tests (RAST) to common aeroallergens. Reference values used were those of ZAPLETAL et al. [13].

Diary cards with missing data were excluded from this analysis. The number of puffs of $\beta_{2}$-agonists used per day was added to the symptom score of that day to derive a severity score. Both the symptom score and the severity score were averaged over 14 days. Variation of PEF was analysed in several ways (table 1). Firstly, for each day, diurnal variation was computed (highest minus lowest value as a percentage of the mean of the two)
Table 1. - Different expressions of peak expiratory flow (PEF) variation used in this study

\begin{tabular}{ll}
\hline Amplitude \% mean & $\begin{array}{l}\text { Mean over 14 days of diurnal PEF vari- } \\
\text { ation }\end{array}$ \\
& $\begin{array}{l}\text { Diurnal variation: (highest PEF - lowest } \\
\text { PEF)/mean of highest and lowest }\end{array}$ \\
Standard deviation of all PEF values \\
recorded over 14 day period \\
Coefficient of variation (SD as a \\
percentage of the mean) of all PEF \\
values recorded over 14 day period \\
Lowest PEF level observed during 14 \\
day period as a percentage of the \\
highest value recorded \\
Day-to-day change \\
$\begin{array}{l}\text { Mean over 14 days of differences in } \\
\text { morning PEF levels between subsequent } \\
\text { days, expressed in absolute values } \\
\left(\mathrm{L} \cdot \mathrm{min}^{-1} \text { ) or as a percentage of mean }\right. \\
\text { morning PEF (day-to-day \% mean) }\end{array}$ \\
\hline
\end{tabular}

and averaged over 14 days (amplitude \% mean). Secondly, the SD and CV of all PEF values recorded over the 2 week period were calculated. Thirdly, the lowest level of PEF observed during the 2 week period was expressed as a percentage of the highest value obtained (low \% best). Finally, mean day-to-day changes of morning PEF were computed in absolute terms $\left(\mathrm{L} \cdot \mathrm{min}^{-1}\right)$ and as a percentage of mean morning PEF (day-to-day \% mean).

Data on PD20, eosinophil counts, and IgE levels were log-transformed before analysis. Because of their highly skewed distributions, symptom and severity scores were analysed using Spearman rank correlation coefficients. The distributions of all other variables were not significantly different from a standard normal distribution; hence, parametric techniques (Pearson correlation coefficients, Student's t-tests) were applied. Data were analysed using Statistical Package for the Social Science (SPSS; Chicago, USA) for Windows ${ }^{\mathrm{TM}}$ version 5.0.1. A p-value of less than 0.05 was considered significant.

\section{Results}

Of the 116 children who completed the baseline period of the study, $102(88 \%)$ filled out their diary cards completely and reliably. Data on these 102 children, whose characteristics are presented in table 2, are used in this paper. These 102 patients were comparable to the entire root population of 116 from which they were drawn with respect to all variables presented in table 2 . The eight patients who had asthma exacerbations during the baseline period were withdrawn from the study. Because their diary data were incomplete, they were not included in the present analysis. Airways obstruction and hyperresponsiveness did not worsen during the baseline period. At the first visit, mean (SE) FEV1 $\%$ pred was $77(1) \%$, at the second visit it was 79 (1)\% (95\% confidence interval $(95 \% \mathrm{CI})$ for difference -5.0 to 0.1 ). Mean (SE) $\log _{2}$ PD20 was $4.2(0.2) \mu \mathrm{g}$ at the beginning and $4.2(0.1) \mu \mathrm{g}$ at the end of the baseline period $(95 \%$ CI for difference -0.3 to 0.2 ). The study group, therefore, comprised children with moderately severe, but clinically stable asthma. The majority 
Table 2. - Characteristics of asthmatic children studied

\begin{tabular}{|c|c|}
\hline Subjects $\mathrm{n}$ & 102 \\
\hline $\operatorname{Sex} \mathrm{M} / \mathrm{F}$ & $75 / 27$ \\
\hline Age yrs & $11 \pm 2$ \\
\hline $\mathrm{FEV}_{1} \%$ pred & $79 \pm 12$ \\
\hline Morning PEF $\mathrm{L} \cdot \mathrm{min}^{-1}$ & $281 \pm 68$ \\
\hline Evening PEF $\mathrm{L} \cdot \mathrm{min}^{-1}$ & $305 \pm 76$ \\
\hline $\begin{array}{l}\log _{2} P D 20 \mu g \\
\text { geometric mean }\end{array}$ & $\begin{array}{l}4.2 \pm 1.5 \\
18.4\end{array}$ \\
\hline $\begin{array}{l}\log _{10} \text { eosinophil count } \times 10^{6} \cdot \mathrm{L}^{-1} \\
\text { geometric mean }\end{array}$ & $\begin{array}{c}2.5 \pm 0.3 \\
333\end{array}$ \\
\hline $\begin{array}{l}\log _{10} \text { serum IgE IU } \cdot L^{-1} \\
\text { geometric mean }\end{array}$ & $\begin{array}{c}2.7 \pm 0.3 \\
535\end{array}$ \\
\hline $\begin{array}{l}\text { Diurnal PEF variation } \\
\text { amplitude } \% \text { mean }\end{array}$ & $13.7 \pm 8.1$ \\
\hline Day-to-day variation in morning & \\
\hline PEF $\mathrm{L} \cdot \mathrm{min}^{-1}$ & $26.0 \pm 14.9$ \\
\hline$\%$ of mean morning PEF & $10 \pm 7$ \\
\hline SD of all PEF recordings $\mathrm{L} \cdot \mathrm{min}^{-1}$ & $33.3 \pm 15.6$ \\
\hline $\mathrm{CV}$ of all PEF recordings \% & $12 \pm 6$ \\
\hline Lowest PEF as $\%$ of patient's best $\%$ & $63 \pm 16$ \\
\hline Symptom score (12-point scale) & $0.36 \quad(0.07-0.86)$ \\
\hline $\begin{array}{l}\text { Doses of inhaled } \beta_{2} \text {-agonist used } \\
\text { daily } \mathrm{n}\end{array}$ & $(0-0.23)$ \\
\hline Daily severity score & $0.50 \quad(0.14-1.09)$ \\
\hline
\end{tabular}

Values are presented as mean \pm SD, or as median and $25-75 \%$ range in parenthesis. M: male; F: female; FEV1: forced expiratory volume in one second; \% pred: percentage of predicted value; PEF: peak expiratory flow; PD20: provocative dose of histamine causing a $20 \%$ fall in FEV1; IgE: immunoglobulin E; CV: coefficient of variation.

of children $(81 \%)$ had used inhaled anti-inflammatory agents before entering the study (28\% sodium cromoglycate, $31 \%$ inhaled steroids, $22 \%$ both). The median age at which their asthma had commenced was 2 yrs; the mean duration of asthma was 7.9 (SD 3.1) yrs. Virtually all patients were atopic; $80 \%$ had a positive RAST to house dust mite.

All indices of PEF variation were comparable between children who had or had not been using inhaled antiinflammatory agents before the study (all p-values $>0.1$ ). Current age, age at onset of asthma, and the duration of asthma were not related to indices of PEF variation. Males showed larger PEF variation than females, most strongly so for amplitude \% mean (male mean (SD) 12 (8)\%, female 17 (8)\%; 95\% CI for difference 1.1-8.1\%).

The correlation coefficients of indices of PEF variation to the degree of airways obstruction, histamine hyperresponsiveness, and markers of atopy are presented in table 3. LogPD20 histamine was significantly related to different indices of PEF variation, most strongly for amplitude \% mean. There was a wide scatter of individual data, however (fig. 1). Markers of atopy were not significantly related to indices of PEF variation.

Table 4 shows the rank correlation coefficients of indices of peak flow variation to symptom and severity scores. Significant associations were found between symptoms and all indices of PEF variation, most strongly for low \% best. Despite being statistically significant, correlations were relatively weak (table 4). Indices of PEF variation were also compared between children with different answers to questions on the standardized respiratory questionnaire. PEF variation was not significantly different between children who had suffered from troublesome wheeze (either spontaneously or
Table 3. - Pearson correlation coefficients of indices of PEF variation during the 2 week observation period to level of lung function, airways hyperresponsiveness, and markers of atopy

\begin{tabular}{lrccc}
\hline & $\begin{array}{c}\text { FEV1 } \\
\% \text { pred }\end{array}$ & $\begin{array}{c}\text { Log } \\
\text { PD20 }\end{array}$ & $\begin{array}{c}\text { Log } \\
\text { eosinophil } \\
\text { counts }\end{array}$ & $\begin{array}{c}\text { Log } \\
\text { IgE }\end{array}$ \\
\hline $\begin{array}{l}\text { Amplitude \% mean } \\
\text { Day-to-day change } \\
\text { (L-min-1) }\end{array}$ & -0.13 & $-0.31^{* *}$ & 0.00 & 0.20 \\
CV of all PEF & -0.15 & -0.17 & 0.04 & 0.08 \\
SD of all PEF & -0.07 & $-0.21^{*}$ & -0.02 & 0.06 \\
Low \% best & 0.15 & $0.22^{*}$ & 0.02 & 0.07 \\
\hline
\end{tabular}

Amplitude \% mean: highest minus lowest peak expiratory flow (PEF) value on each day, expressed as a percentage of their mean, averaged over 14 days; day-to-day change: difference between morning PEF values on consecutive days, averaged over 14 days; CV: coefficient of variation of all PEF values recorded over 14 days; SD: standard deviation of all PEF values recorded over 14 days; Low \% best: lowest PEF recorded over a 14 day period, expressed as a percentage of the best PEF recorded during that 14 day period. For further definitions see legend to table 2 . *: $\mathrm{p}<0.05$; **: $\mathrm{p}<0.01$, significance of relationships to indices of PEF variation.

induced by wheeze or colds) or cough in the past year and children who had not $(\mathrm{p}>0.1)$. Children who had experienced one or more exacerbations of asthma requiring systemic steroids in the past year, however, had significantly higher PEF variation (mean (SEM) amplitude $\%$ mean $15(1) \%)$ than children without such exacerbations (10 (1)\%, 95\% CI for difference 1.4-8.6\%).

An example of a chart of PEF values of an individual patient is presented in figure 2 . This patient, a 12 year old boy, had a marked drop in PEF on days 1012. The values for different indices of PEF variation for this period in this patient are given in the legend to figure 2 .

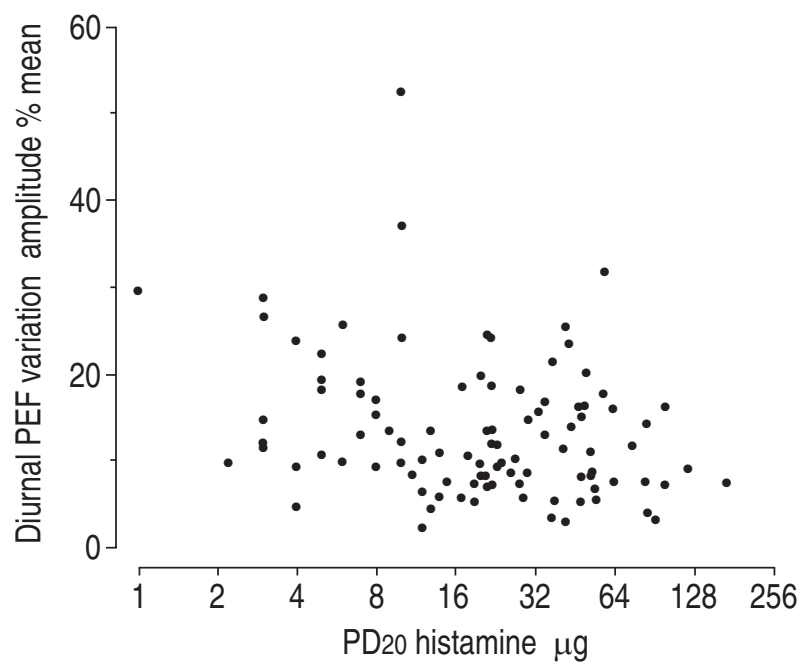

Fig. 1. - Scatter plot of the relationship between PD20 histamine and diurnal PEF variation (expressed as amplitude \% mean, i.e. highest minus lowest PEF value on each day, expressed as percentage of their mean, averaged over 14 days). The correlation between diurnal $\mathrm{PEF}$ variation and $\log \mathrm{PD} 20$ is statistically significant $(\mathrm{r}=-0.31 ; \mathrm{p}<0.01)$ but there is a wide scatter of individual data. PEF: peak expiratory flow; PD20: provocative dose of histamine causing a $20 \%$ fall in forced expiratory volume in one second. 
Table 4. - Spearman rank correlation coefficients of indices of PEF variation during the 2 week observation period to symptom scores recorded simultaneously on diary cards

\begin{tabular}{lcc}
\hline & $\begin{array}{c}\text { Daily symptom } \\
\text { score }\end{array}$ & $\begin{array}{c}\text { Clinical severity } \\
\text { score }\end{array}$ \\
\hline Amplitude \% mean & $0.27 * *$ & $0.32 * *$ \\
Day-to-day change & $0.20^{*}$ & $0.32 * *$ \\
$\left(\mathrm{~L} \cdot \mathrm{min}^{-1}\right)$ & & \\
CV of all PEF & $0.31 * *$ & $0.36 * *$ \\
SD of all PEF & $0.26 * *$ & $0.31 * *$ \\
Low \% best & $-0.34 * *$ & $-0.39 * *$ \\
\hline
\end{tabular}

For definitions see legend to figure 3 .

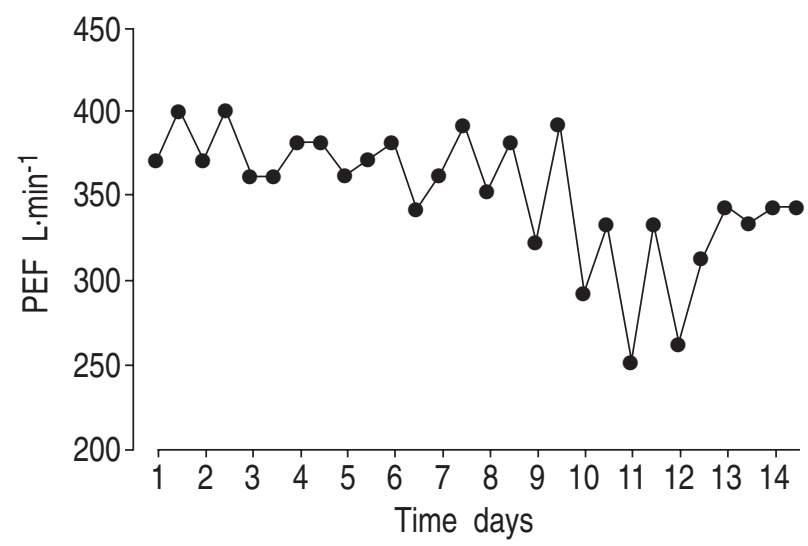

Fig. 2. - Home recorded PEFs of a 12 year old boy with asthma. There is a clinically important reduction of PEF on days 10-12. The average amplitude $\%$ mean over this period is $9 \%$, the average day-to-day variation $11 \%$. The SD of all PEF measurements is 38.1 $\mathrm{L} \cdot \mathrm{min}^{-1}$, the coefficient of variation is $11 \%$. The lowest recorded PEF in this period is $250 \mathrm{~L} \cdot \mathrm{min}^{-1}$ (on day 11), which is $62 \%$ of the highest recorded PEF value (400 L·min ${ }^{-1}$, on days 1 and 2, pm). For definitions see legend to figure 1 .

Figure 3 displays the frequency distribution of three indices of PEF variation in the entire study population, namely amplitude \% mean (which is the most commonly applied method), SD (which is statistically the most appropriate method to express variation), and low \% best (which can be easily calculated in the office without the use of electronic equipment).
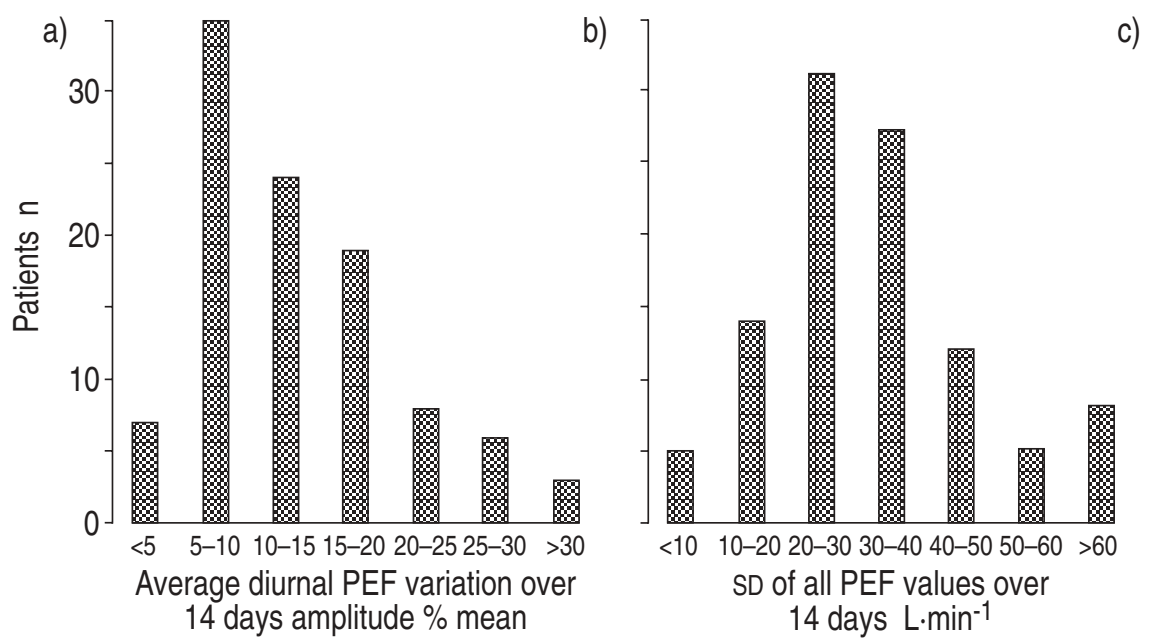

\section{Discussion}

This study shows that, in a group of children whose asthma is clinically stable during a 4 week period of treatment with only inhaled $\beta_{2}$-agonists, variation of PEF is significantly related to simultaneously recorded symptom scores and to airways hyperresponsiveness to histamine. This is in accordance with results of other studies, both in children [5, 6] and adults [8, 14]. The correlations, although statistically significant, are weak. In an early study by RYAN et al. [15] a much stronger correlation $(\mathrm{r}=-0.81)$ was described between diurnal PEF variation and histamine responsiveness. In this study, however, diurnal PEF variation was computed as the difference between the highest PEF after salbutamol minus the lowest PEF before salbutamol. This way of expressing PEF variation, which adds pharmacologically induced variation in PEF to spontaneously occurring changes, may not be valid and has not been used by others. Nevertheless, the paper by RYAN et al. [15] is commonly quoted as evidence that diurnal PEF variation reflects airways responsiveness to histamine or other stimuli.

The results presented here, along with those observed by others $[5,6,8,14]$, strongly suggest that diurnal PEF variation and airways hyperresponsiveness are distinct, though related, phenomena in asthma, and that neither measurement can be used as a proxy for the other. The same applies to symptom scores, which were also significantly, but weakly, related to PEF variation $[5,6]$. In our study sample, PEF variation was not related to markers of atopy. This is in contrast to the findings of an epidemiological study [5]. Because the vast majority of children in our study were atopic, our study probably lacked the contrast to demonstrate an effect of atopy on PEF variation.

The expression of PEF variation is a contentious issue. Most clinicians will inspect a chart of home PEF recordings looking for changes in level or variation of $\mathrm{PEF}$, without actually calculating numerical values. The most commonly used calculation of PEF variation is the amplitude \% mean, which averages diurnal variation in PEF over a number of days [6, 9]. This and other indices, which average diurnal variation over time, have the disadvantage that they "may fail to recognize a small

Fig. 3. - Distribution of three indices of PEF variation during the 2 week observation period in 102 children with asthma, clinically stable on inhaled $\beta_{2}$-agonists alone during 4 weeks. a) Average daily amplitude $\%$ mean; b) SD of all PEF recordings; and c) lowest PEF as percentage of the patient's best. For definitions see legend to figure 1 . 
number of clinically important low PEF values in an otherwise homogeneous distribution" [10]. This is illustrated in figure 2: this patient had a clinically important drop in PEF on days 10-12, but the average amplitude $\%$ mean over this period was $9 \%$, which is well within the "normal" range, reported to be $<31 \%$ in asymptomatic children [16]. If this definition had been used in our study, $97 \%$ of patients with asthma would have had a "normal" amplitude \% mean. Sixty five per cent of patients had amplitude $\%$ mean values $<15 \%$, which is the cut-off level most commonly used in self-management plans (fig. 3a).

Our results, therefore, confirm earlier observations that amplitude \% mean does not reliably identify reductions in PEF if they are isolated or short-term [10]. Such isolated or short-term reductions in PEF, which are very common in asthmatic children [17], may be better appreciated by calculating the SD (fig. 3b) or the $\mathrm{CV}$ of all PEF values recorded over a period of time. Although this approach is statistically and scientifically valid, these numbers cannot be calculated quickly and manually. As a result, using SD or $\mathrm{CV}$ as an index of PEF variation is not feasible in clinical practice. Conversely, calculating the lowest PEF as a percentage of the highest PEF value can be performed quickly and easily in the office. This index correlates as strongly to symptom scores, airways obstruction and hyperresponsiveness as do other expressions of PEF variation (tables 3 and 4). The example in figure 2 illustrates that this expression does identify short-term or isolated drops in $\mathrm{PEF}$. The present index resembles that recently introduced by REDDEL et al. [18], who recommended the minimum morning PEF over a one week period as percentage of personal best value. Indeed, this parameter was also related to airways hyperresponsiveness in asthmatic adults [18].

Based on the present findings, we therefore propose the expression of PEF variation as the lowest recorded $\mathrm{PEF}$ as a percentage of the patient's best (over short periods of time) in future studies. Obviously, a prerequisite for using this index reliably is the absence of a single high or low outlying PEF value, which could be due to a technically unsatisfactory manoeuvre. Before low $\%$ best is calculated, therefore, inspection of the results for such outliers is recommended.

The distribution of low \% best in our group of children with asthma is presented in figure $3 \mathrm{c}$. Ninety five per cent of all patients had a lowest PEF $<85 \%$ of their best value. Two population studies in children reported data on the distribution of PEF variation in healthy subjects. Ninety five per cent of these healthy children aged $6-14$ yrs had a lowest $\%$ best of $>80 \%$ [16], and 95\% of healthy adolescents aged $12-15$ yrs had a lowest PEF as a percentage of the mean (rather than the highest) PEF of more than 90\% [10]. From these data, it appears reasonable to propose that a lowest PEF higher than 80$90 \%$ of the highest PEF in a given subject can be interpreted as "normal".

Despite the fact that these children had moderately severe asthma, most of them tolerated withdrawal or reduction of inhaled anti-inflammatory medication well during the 4 week baseline period. Very few patients were withdrawn from the study during the baseline period due to worsening of their asthma, and FEV $1 \%$ pred and
PD20 histamine did not deteriorate. This is in contrast to findings in adult asthmatics, in whom FEV $1 \%$ pred and $\mathrm{PC} 20$ histamine deteriorated significantly during an identical baseline period after withdrawal of inhaled antiinflammatory agents [19]. We have previously found that, after withdrawal of inhaled steroid treatment, it takes 1-2 months before an aggravation of airways obstruction and hyperresponsiveness becomes apparent [20]. The fact that this occurs more quickly in adults [19], added to the finding that maintenance treatment with inhaled steroids in children results in more pronounced reduction of airways hyperresponsiveness [7] than it does in adults [21], may suggest that asthma in children responds more favourably than asthma in adults to inhaled steroid treatment. This could be viewed as support for the hypothesis that, in asthma, anti-inflammatory treatment should be instituted at an early stage of the disease [22, 23].

In conclusion, peak expiratory flow variation in children with clinically stable asthma is significantly, but weakly, related to symptoms and hyperresponsiveness. Expressing peak expiratory flow variation in terms of the lowest recorded peak expiratory flow as a percentage of the highest value obtained is easy to perform, will pick up isolated or short-term episodes of reduced peak expiratory flow, and is clinically appealing. Lowest peak expiratory flow less than $80-90 \%$ of the highest peak expiratory flow (recorded over a short period of time) may be considered as reduced, or abnormal.

\section{The Dutch CNSLD Study Group}

The Dutch CNSLD Study Group consists of a steering committee (K.F. Kerrebijn, Ph.H. Quanjer and H.J. Sluiter), members from the Depts of Pulmonology of the University Hospital of Amsterdam (E.M. Pouw, D.F.M.E. Schoonbrood, C.M. Roos, H.M. Jansen), Groningen (A. De Gooijer, H.A.M. Kerstjens, D.S. Postma, Th.W. van der Mark, H.J. Sluiter, G.H. Koëter), Leiden (P.M. de Jong, P.J. Sterk, A.M.J. Wever, J.H. Dijkman), Nijmegen (P.N.R. Dekhuijzen, H.T.M. Folgering, C.L.A. van Herwaarden), Rotterdam (S.E. Overbeek, J.M. Bogaard, C. Hilvering), and Utrecht (S.J. Gans, H.J.J. Mengelers, B.A.H.A. van der Bruggen-Bogaarts, J. Kreukniet), the Depts of Paediatric Pulmonology of the Sophia Children's Hospital, Rotterdam (E.E.M. van EssenZandvliet, K.F. Kerrebijn), the Juliana Children's Hospital, the Hague (E.J. Duiverman, J.M. Kouwenberg, J.E. Prinsen), and the Beatrix Children's Hospital, Groningen (P.L.P. Brand, H.J. Waalkens, J. Gerritsen, K. Knol), the Dept of Allergology, University Hospital Groningen (J.G.R. de Monchy), the Dept of General Practice, Leiden University (F.W. Dekker, A.A. Kaptein), the Dept of Physiology, Leiden University (P.J.F.M. Merkus, Ph.H. Quanjer), The Netherlands. Scientific counsel: S.J. Pocock, M.D. Hughes, and N.J. Robinson (London), and E.R. Bleecker and D.A. Meyers (Baltimore, USA).

\section{References}

1. Joint Task Force on Practice Parameters. Practice parameters for the diagnosis and treatment of asthma. $J$ Allergy Clin Immunol 1995; 96 (Suppl.): 858-870.

2. Anonymous. Asthma: a follow-up statement from an international paediatric asthma consensus group. Arch Dis Child 1992; 67: 240-248.

3. British Thoracic Society and others. Guidelines for the management of asthma: a summary. BMJ 1993; 306: 776-782.

4. American Thoracic Society. Standards for the diagnosis and care of patients with chronic obstructive pulmonary disease (COPD) and asthma. Am Rev Respir Dis 1987; 136: 225-244. 
5. Clough JB, Williams JD, Holgate ST. Effect of atopy on the natural history of symptoms, peak expiratory flow, and bronchial responsiveness in 7 and 8 year old children with cough and wheeze. Am Rev Respir Dis 1991; 143: 755-760.

6. Gern JE, Eggleston PA, Schuberth KC, et al. Peak flow variation in childhood asthma: a three year analysis. $J$ Allergy Clin Immunol 1994; 93: 706-716.

7. van Essen-Zandvliet EEM, Hughes MD, Waalkens HJ, et al. Effects of 22 months of treatment with inhaled corticosteroids and/or $\beta_{2}$-agonists on lung function, airway responsiveness, and symptoms in children with asthma. Am Rev Respir Dis 1992; 146: 547-554.

8. Kerstjens HAM, Brand PLP, de Jong PM, Koëter GH, Postma DS, Dutch CNSLD Study Group. Influence of treatment on peak expiratory flow and its relation to airway hyperresponsiveness and symptoms. Thorax 1994; 49: 1109-1115.

9. Higgins B, Britton JR, Chinn S, et al. The distribution of peak expiratory flow variability in a population sample. Am Rev Respir Dis 1989; 140: 1368-1372.

10. Siersted HC, Hansen HS, Hansen N-CG, Hyldebrandt N, Mostgaard G, Oxhoy H. Evaluation of peak expiratory flow variability in an adolescent population sample: the Odense schoolchild study. Am J Respir Crit Care Med 1994; 149: 598-603.

11. Charlton I, Antoniou AG, Atkinson J, et al. Asthma at the interface: bridging the gap between general practice and a district general hospital. Arch Dis Child 1994; 70: 313-318.

12. Brand PLP, Kerstjens HAM, Postma DS, Dutch CNSLD Study Group. Long-term clinical trials in obstructive lung disease: principles and practice. Pharmaceut Med 1992; 5: 263-289.

13. Zapletal A, Samanek M, Paul T. Lung function in children and adolescents: methods, reference values. In Zapletal A, ed. Progress in Respiration Research. 1987; 22: 114-218.

14. Brand PLP, Postma DS, Kerstjens HAM, Koëter GH,
Dutch CNSLD Study Group. Relationship of airway hyperresponsiveness to respiratory symptoms and diurnal peak flow variation in obstructive lung disease. Am Rev Respir Dis 1991; 143: 916-921.

15. Ryan G, Latimer KM, Dolovich J, Hargreave FE. Bronchial responsiveness to histamine: relationship to diurnal variation of peak flow rate, improvement after bronchodilator, and airway calibre. Thorax 1982; 37: 423-429.

16. Quackenboss JJ, Lebowitz MD, Krzyzanowski M. The normal range of diurnal changes in peak expiratory flow rates: relationship to symptoms and respiratory disease. Am Rev Respir Dis 1991; 143: 323-330.

17. Clough JB, Holgate ST. Episodes of respiratory morbidity in children with cough and wheeze. Am J Respir Crit Care Med 1994; 150: 48-53.

18. Reddel HK, Salome CM, Peat JK, Woolcock AJ. Which index of peak expiratory flow is most useful in the management of stable asthma? Am J Respir Crit Care Med 1995; 151: 1320-1325.

19. Brand PLP, Kerstjens HAM, Postma DS, et al. Longterm multicentre trial in chronic nonspecific lung disease: methodology and baseline assessment in adult patients. Eur Respir J 1992; 5: 21-31.

20. Waalkens HJ, van Essen-Zandvliet EEM, Hughes MD, et al. Cessation of long-term treatment with inhaled corticosteroid (budesonide) in children with asthma results in deterioration. Am Rev Respir Dis 1993; 148: 1252-1257.

21. Kerstjens HAM, Brand PLP, Hughes MD, et al. A comparison of bronchodilator therapy with or without inhaled corticosteroid therapy for obstructive airways disease. $N$ Engl J Med 1992; 327: 1413-1419.

22. Agertoft L, Pedersen S. Effects of long-term treatment with an inhaled corticosteroid on growth and pulmonary function in asthmatic children. Respir Med 1994; 88: 373-381.

23. Haahtela T, Jarvinen M, Kava T, et al. Effects of reducing or discontinuing inhaled budesonide in patients with mild asthma. N Engl J Med 1994; 331: 700-705. 